\title{
The effect of omeprazole on gastric myoelectrical activity and emptying
}

\author{
Takeshi KAMIYA ${ }^{1}$, Michiko SHIKANO ${ }^{1}$, Mamoru TANAKA ${ }^{1}$, \\ Hironobu TsukAmoto ${ }^{1}$, Masahide EBI ${ }^{1}$, Yoshikazu HiRATA ${ }^{1}$, \\ Takashi Mizushima ${ }^{1}$, Kenji MuraKAmi ${ }^{1}$, Takaya SHIMURA ${ }^{1}$, \\ Tsutomu Mizoshita ${ }^{1}$, Yoshinori Mori ${ }^{1}$, Satoshi TANIDA ${ }^{1}$, \\ Takashi KATO ${ }^{1}$, Kenro IMAEDA ${ }^{1}$, Hiromi KATAOKA ${ }^{1}$ and \\ Takashi $\mathrm{JOH}^{1}$ \\ ${ }^{1}$ Department of Gastroenterology and Metabolism, Nagoya City University Graduate School \\ of Medical Sciences, Japan
}

Received April 19, 2011; Accepted May 9, 2011

\begin{abstract}
Omeprazole, a proton pump inhibitor, is widely used for the treatment of patients with peptic ulcer, gastroesophageal reflux disease and functional dyspepsia (FD), although some studies have demonstrated that omeprazole delays gastric emptying. The purpose of this study was to investigate the efficacy of omeprazole on gastric motility including gastric myoelectrical activity and gastric emptying. This study was performed on 12 healthy volunteers. Gastric motility was evaluated with cutaneously recorded electrogastrography (EGG) and gastric emptying of semi-solid meals using the ${ }^{13} \mathrm{C}$-acetic acid breath test. EGG and gastric emptying were measured before and after treatment with $20 \mathrm{mg}$ omeprazole orally for 7 days. In the fasting state, the percentage of EGG normogastria increased significantly compared to the baseline. No significant changes were observed in other EGG parameters including the percentage of tachygastria and bradygastria in both fasting and postprandial states, and the power ratios between both before and after ingestion of omeprazole. In addition, administrated omeprazole did not show any significant differences in the gastric emptying parameters such as the half emptying time. We conclude that administration of omeprazole did not affect gastric motility but improved gastric myoelectrical activity. These effects of omeprazole may be one of the mechanisms involved in its efficacy in relieving dyspeptic symptoms in FD patients.
\end{abstract}

Key words: omeprazole, functional dyspepsia, electrogastrography, gastric emptying

\section{Introduction}

Functional dyspepsia (FD) is a common disease characterized by the presence of persistent or recurrent epigastric pain, early satiation and postprandial fullness in the absence of organic disease

Correspondence to: Takeshi Kamiya, M.D., PhD., Department of Gastroenterology and Metabolism, Nagoya City University Graduate School of Medical Sciences, 1-Kawasumi, Mizuho-cho, Mizuho-ku, Nagoya 4678601, Japan

Phone: +81-52-853-8211 Fax: +81-52-852-0952 e-mail: kamitake@med.nagoya-cu.ac.jp 
(Talley et al., 1999; Tack et al., 2006). A variety of factors contribute to the cause of such symptoms. These include hypersensitivity to gastric acid or distension, disturbed gastric motility, impaired accommodation to a meal, central nervous system dysfunction or Helicobacter pylori infection. Gastric motor abnormalities are also thought to be a further factor.

Proton pump inhibitors (PPIs) effectively suppress gastric acid secretion. Omeprazole is the first PPI available clinically and is widely used for the treatment of patients with either a peptic ulcer or gastroesophageal reflux disease (GERD). In addition, omeprazole has been reported to be effective in the treatment of patients with FD, and in the relief of dyspeptic symptoms such as upper abdominal pain, nausea and indigestion. Several reports which have examined the effect of omeprazole on gastric emptying have yielded controversial results; in some of these, gastric emptying was found to be delayed (Benini et al., 1996; Rasmussen et al., 1997; Parkman et al., 1998; Tougas et al., 2005), while in others it was unchanged (Cecil et al., 2004; Miyasaka et al., 2004; Egorin et al., 2009).

As the effect of omeprazole on gastric myoelectrical activity has not been reported, this study has made simultaneous measurements of gastric myoelectrical activity and gastric emptying both before and after the administration of omeprazole to investigate the efficacy of omeprazole on these gastric motility parameters.

\section{Materials and Methods}

\section{Subjects}

The study was performed on 12 healthy volunteers between 26 and 45 years of age with no history of gastrointestinal disorders. Table 1 shows the characteristics of the subjects (Table 1). Written informed consent was obtained from all subjects prior to the study in accordance with the Declaration of Helsinki (2008). The study protocol was approved by the Medical Ethical Committee of the Nagoya City University Graduate School of Medical Sciences.

\section{Experimental procedure}

Gastric myoelectrical activity was evaluated with cutaneously recorded electrogastrography (EGG), while gastric emptying was measured using the ${ }^{13} \mathrm{C}$-acetic acid breath test. After fasting for at least 6 hours, the EGG was recorded for $30 \mathrm{~min}$ in the supine position. The subjects then ingested $100 \mathrm{mg}$ of ${ }^{13} \mathrm{C}$-acetic acid mixed with a semi-solid test meal (Jelly Ace, House Foods, Osaka, Japan; $200 \mathrm{ml}$ of jelly, containing $4.4 \mathrm{~g}$ protein, $0.4 \mathrm{~g}$ fat, $42.0 \mathrm{~g}$ carbohydrate, with an energy content of $190 \mathrm{kcal}$;). Immediately following consumption, EGG recording was repeated for a further $30 \mathrm{~min}$. All subjects at first underwent an EGG and a gastric emptying test, and then given $20 \mathrm{mg}$ omeprazole orally once daily for 7 days. Gastric motility was measured again following the 7-day treatment period.

\section{Recording and analysis of EGG}

The methodology has been previously published elsewhere (Hirako et al., 2005). In brief, the EGG was measured using a portable EGG recorder (NIPRO EG; A\&D Company, Tokyo, Japan). The EGG electrode was placed halfway between the xiphoid process and the navel, while the other 
four electrodes were respectively placed above and below and to the left and right of the stomach. The EGG data was transferred to a personal computer (Deskpower TIX 507; Fujitsu, Tokyo, Japan) via an RS-232C port. Dominant frequencies and their amplitudes (peak powers) were obtained from four channel EGGs recorded both at fasting and following the meal by fast fourier transformation (FFT) analysis, and the mean values of the four channels were calculated respectively.

The following parameters were calculated and evaluated for each subject.

1. Percentage of normogastria: defined as the percentage of time during which normal 2-4 cycle per min (cpm) slow waves were present over the entire observation period. This parameter reflects the regularity of the gastric myoelectrical activity.

2. Percentage of tachygastria and bradygastria: defined as the percentage of time during which over $4 \mathrm{cpm}$ and under $2 \mathrm{cpm}$ slow waves were present respectively. These parameters reflect the irregularity of the gastric myoelectrical activity.

3. Power ratio: defined as the ratio of after to before meal intake EGG peak power values (i.e., postprandial/fasting), where the peak power refers to the power at EGG dominant frequency. Changes in EGG peak power seem to reflect gastric contractility (Smout et al., 1980; Hamilton et al., 1986; Chen et al., 1994; Sun et al., 1995).

\section{Measurement of gastric emptying}

Breath samples were collected in polyethylene storage bags before the test meal as a baseline, then at 15 -min intervals during the two hours after the test meal. The amount of ${ }^{13} \mathrm{C}$ in the breath storage bags was measured by infrared isotope spectrometry (UBiT-IR300, Otsuka Electronics, Osaka, Japan). Half-emptying time $\left(T_{1 / 2}\right)$ and lag time $\left(T_{\text {lag }}\right)$ were calculated as described by Ghoos et al. (1993): $T_{1 / 2}$ is defined as the area under the fitted curve until half of the dose of the cumulative ${ }^{13} \mathrm{C}$ excretion is excreted when time is infinite, and $T_{\text {lag }}$ is the time corresponding to the maximum ${ }^{13} \mathrm{C}$ excretion of the fitted curve. These two parameters were used to assess the degree of gastric emptying.

\section{Statistical analysis}

All data were expressed as the mean \pm SD using the Student's $t$-test (paired and unpaired). A $P$-value of less than 0.05 was considered to be a statistically significant difference.

\section{Results}

\section{Electrogastrography and gastric emptying}

The percentage of normal 2-4 cpm slow wave in a fasting state before the intake of omeprazole was $67.3 \pm 6.9 \%$. After administration of omeprazole, the percentage of normogastria increased significantly compared to the baseline (Fig. 1). During the postprandial state, the percentage of normogastria before and after the administration of omeprazole was $68.1 \pm 11.9 \%$ and $71.6 \pm 10.3 \%$, respectively. No significant changes in the percentage of tachygastria and bradygastria were observed both before and after the ingestion of omeprazole between both the fasting and postprandial states (Fig. 1, Table 1). In addition, the mean power ratio did not show a 


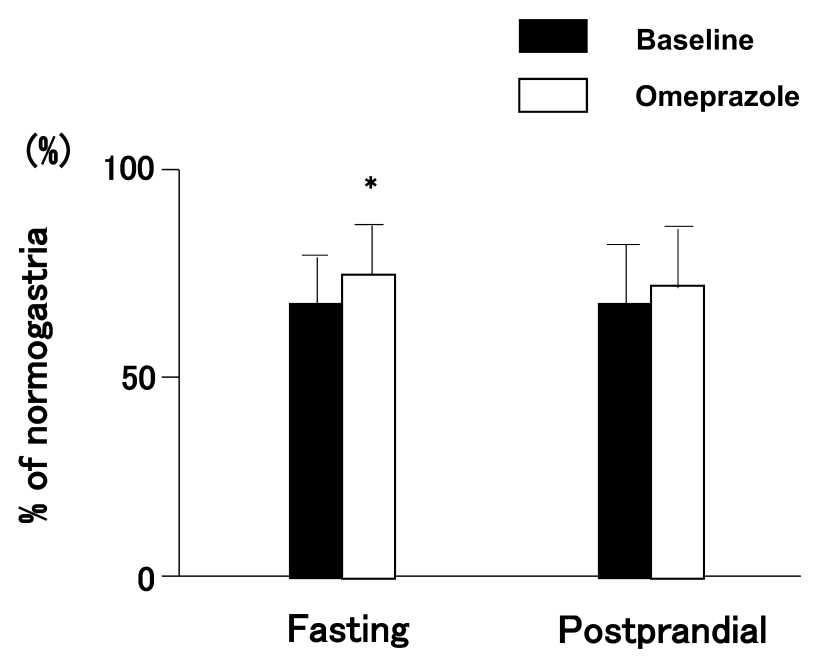

Fig. 1. Percentage of normogastria in Electrogastrograms from the baseline (shaded bars) and after the administration of omeprazole (FD; outlined bars). Data values are presented as mean $\pm \mathrm{SD}$. *, $P<0.05$ vs. baseline.

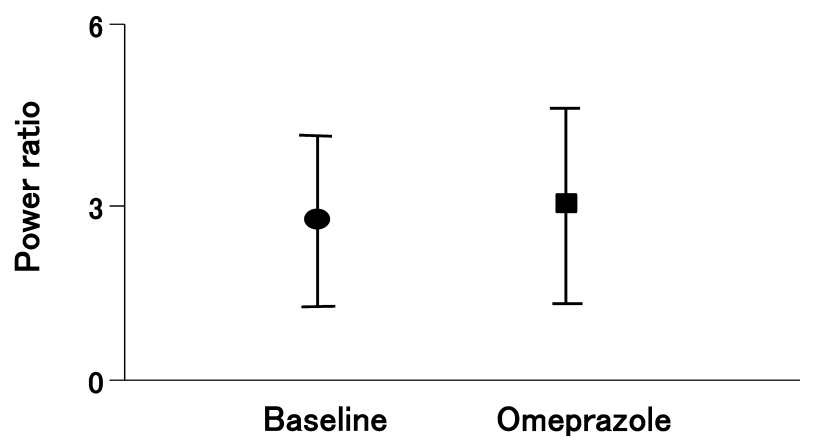

Fig. 2. Power ratio in the Electrogastrogram from the baseline (shaded circle) and after the administration of omeprazole (shaded square). Data values are presented as mean \pm SD.

significant change after administration of omeprazole (Fig. 2).

In overall analysis, there were no significant differences in the ${ }^{13} \mathrm{C}$-acetic acid breath test $\left(\mathrm{T}_{1 / 2}\right.$ and $\mathrm{T}_{\text {lag }}$ ) taken both before and after the ingestion of omeprazole (Fig. 3). Changes in the values of $\mathrm{T}_{1 / 2}$ for each subject can be found in Fig. 4. These results mean that omeprazole did not affect gastric emptying.

\section{Discussion}

The findings of this study are as follows: (1) After administration of omeprazole, the percentage of EGG normogastria during fasting increased significantly compared to the baseline. (2) The EGG power ratio did not show a significant change after administration of omeprazole. (3) 
Table 1. Change in percentage of EGG frequency parameters

\begin{tabular}{lllc}
\hline & & Baseline & Omeprazole \\
\hline Fasting EGG & Normogastria (\%) & $67.3 \pm 6.9$ & $75.4 \pm 9.2^{*}$ \\
& Tachygastria (\%) & $17.1 \pm 2.5$ & $14.4 \pm 3.0$ \\
& Bradygastria (\%) & $11.6 \pm 1.5$ & $10.2 \pm 3.3$ \\
Postprandial EGG & Normogastria (\%) & $68.1 \pm 11.9$ & $71.6 \pm 10.3$ \\
& Tachygastria (\%) & $20.4 \pm 5.4$ & $18.7 \pm 6.3$ \\
& Bradygastria (\%) & $11.5 \pm 4.8$ & $9.7 \pm 5.6$ \\
\hline
\end{tabular}

*, $P<0.05 v s$. baseline, Values are means \pm SD. EGG: electrogastrogram.

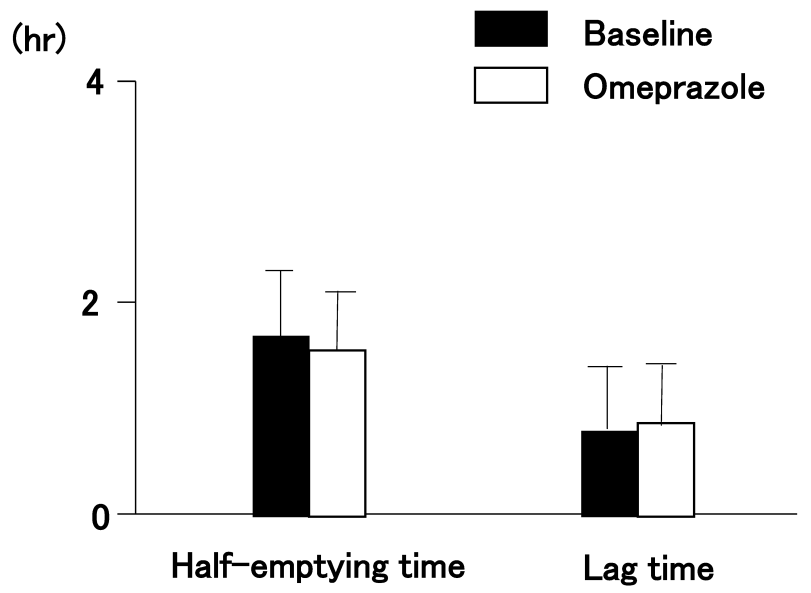

Fig. 3. Gastric emptying, expressed as lag time and half-emptying time, in ${ }^{13} \mathrm{C}$-acetic acid breath test for the baseline (shaded bars) and after the administration of omeprazole (outlined bars). Data values are presented as mean $\pm \mathrm{SD}$.

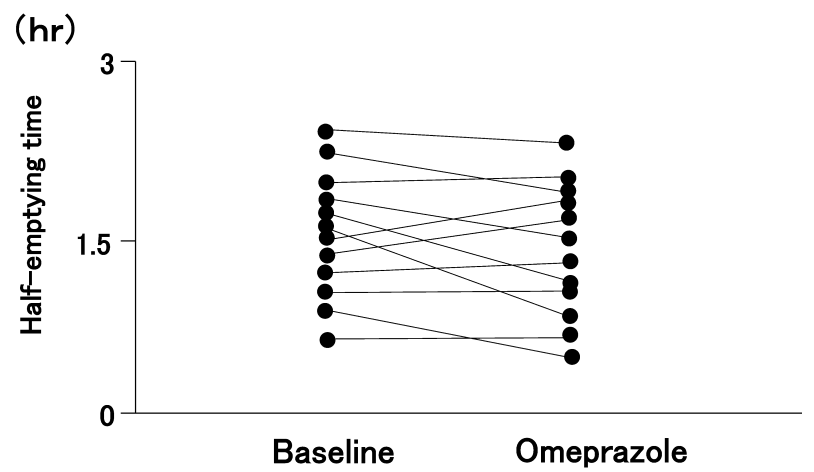

Fig. 4. Changes of half-emptying time in ${ }^{13} \mathrm{C}$-acetic acid breath test in each subject. Connected pairs of points represent individual values before and after treatment.

No significant changes were observed in the values of the gastric emptying parameters between the baseline and following the ingestion of omeprazole.

An interesting finding in this study is that the percentage of EGG normogastria increased 
significantly during the fasting state after administration of omeprazole. The stomach muscle has a myogenic mechanism that modulates its motility. Gastric myoelectrical activity is composed of slow waves and spike potentials (Smout et al., 1980), and it is thought to be essential for determining stomach movement. EGG is a method which enables gastric electrical activity to be recorded using abdominal surface electrodes. This finding suggests that the administration of omeprazole may influence gastric slow waves and improve the rhythm of gastric myoelectrical activity.

No significant changes were observed in other EGG parameters such as the power ratio or the percentage of arrhythmia after the ingestion of omeprazole in both fasting and postprandial states. Many previous studies suggest that abnormal EGG findings relate to dyspeptic symptoms. Various EGG findings have been demonstrated in patients with FD in prior studies (Geldof et al., 1986, Jebbink et al., 1995, Parkman et al., 1997, Lin et al., 1999); these included a low percentage of normogastria, a higher percentage of arrhythmia and a decreased power ratio. Lin $e$ al. reported that approximately $40 \%$ of patients with FD have abnormal gastric myoelectrical activity (Lin et al., 1999). Geldof et al described electrogastrographic abnormalities present in 48 patients with unexplained nausea and vomiting (Geldof et al., 1986). Abnormal gastric electrical rhythm detected by EGG has been described in patients with diabetic gastropathy (Koch et al., 1989, Mathur et al., 2001), anorexia nervosa (Abell et al., 1987) and motion sickness (Stern et al., 1987). Since the subjects enrolled in this study were all healthy volunteers with no abdominal symptoms, EGG findings might not show significant changes except in the percentage of normogastria during fasting after administration of omeprazole.

Gastric emptying did not show a significant difference after the intake of omeprazole. Several studies evaluating the effect of omeprazole on gastric emptying as described in the introduction have yielded conflicting results. Tougas et al. (2005) demonstrated treatment with $20 \mathrm{mg}$ omeprazole for 14 days caused a statistically significant delay in gastric emptying by the isotope method in healthy male volunteers. Other reports showed the magnitude of the delay in gastric emptying produced by omeprazole to range from $15 \%$ to as much as $40 \%$ (Benini et al., 1996, Rasmussen et al., 1997, Parkman et al., 1998). In addition, omeprazole (40-150 mg/kg, i.p. once daily for 5 days) delayed gastric emptying in a dose-related manner in mice (Cowan et al., 2005). In these reports, inadequate hydrolysis of food, enhanced secretion of gastrins which antagonize gastric emptying, and increased viscosity of gastric contents bringing about decreased fluid secretion etc., are speculated as the reasons for delayed gastric emptying following omeprazole ingestion. These possible mechanisms are based largely on the potential consequence of omeprazole-induced suppression of gastric acid.

On the other hand, Cecil et al reported that there was no significant difference in gastric emptying between a single oral dose of $80 \mathrm{mg}$ omeprazole and a placebo when evaluated by scintigraphy in healthy male subjects (Cecil et al., 2004). Another report (Egorin et al., 2009) showed that administration of $40 \mathrm{mg}$ omeprazole orally for 5 days did not significantly affect the pharmacokinetics of imatinib, which has revolutionized the treatment of chronic myeloid leukemia and gastrointestinal stromal tumors. Anjiki et al. (2005) showed that rabeprazole, another PPI, has dual effects on solid gastric emptying: in initial acceleration and with a subsequent decrease, as assessed by the ${ }^{13} \mathrm{C}$-octanoate breath test. In our study, gastric emptying remained unchanged 
compared with the baseline using ${ }^{13} \mathrm{C}$-acetic acid breath test. Discrepancies among these findings may be due to methodological differences in the measurement of gastric emptying, or the dose or duration of omeprazole ingestion. No data are available to explain these results.

Delayed gastric emptying has been proposed as one of the key mechanisms that underlies symptom generation in FD. Several studies evaluating gastric emptying in patients with FD have been reported (Stanghellini et al., 1996, Maes et al., 1997, Perri et al., 1998, Sarnelli et al., 2003). These studies describe delayed gastric emptying in 20 to $40 \%$ of cases. In a meta-analysis of 17 studies (Quartero et al., 1998), a significant delay of solid gastric emptying was present in almost $40 \%$ of FD patients. Omeprazole has been used in the treatment of FD as described in the introduction. The effect of omeprazole on gastric myoelectrical activity and on gastric emptying has not been reported in FD patients. Delayed gastric emptying may be improved by omeprazole intake through the improvement of gastric myoelectrical activity. Further studies are needed to clarify the effect of omeprazole on gastric motility in FD patients.

In conclusion, this is the first study to investigate the effect of omeprazole on gastric myoelectrical activity and gastric emptying simultaneously in healthy volunteers. In this study, the percentage of EGG normogastria in the fasting state significantly increased and gastric emptying did not change after the ingestion of omeprazole. These effects of omeprazole may be one of the mechanisms of its efficacy in relieving dyspeptic symptoms in FD patients.

\section{References}

Abell, T.L., Malagelada, J.R., Lucas, A.R., Brown, M.L., Camilleri, M., Go, V.L.W., Azpiroz, F., Callaway, C.W., Kao, P., Zinsmeister, A.R. and Huse, D.M. (1987). Gastric electromechanical and neurohormonal function in anorexia nervosa. Gastroenterology 93: 958-965.

Adachi, H., Kamiya, T., Hirako, M., Misu, N., Kobayashi, Y., Shikano, M., Matsuhisa, E., Kataoka, H., Sasaki, M., Ohara, H., Nakao, H., Orito, E. and Joh, T. (2007). Improvement of gastric motility by hemodialysis in patients with chronic renal failure. J. Smooth Muscle Res. 43: 179-189.

Anjiki, H., Sanaka, M. and Kuyama, Y. (2005). Dual effects of rabeprazole on solid-phase gastric emptying assessed by the ${ }^{13} \mathrm{C}$-octanoate breath test. Digestion 72: 189-194.

Benini, L., Castellani, G., Bardelli, E., Sembenini, C., Brentegani, M.T., Caliari, S. and Vantini, I. (1996). Omeprazole causes delay in gastric emptying of digestible meals. Dig. Dis. Sci. 41: 469-474.

Cecil, J.E., Francis, J. and Read, N.W. (2004). Investigation into the role of cephalic stimulation of acid secretion on gastric emptying and appetite following a soup meal using the gastric acid inhibition omeprazole. Appetite 42: 99-105.

Chen, J.D.Z., Richards, R.D. and McCallum, R.W. (1994). Identification of gastric contractions from the cutaneous electrogastrogram. Am. J. Gastroenterol. 8: 79-85.

Cowan, A., Earnest, D.L., Ligozio, G. and Rojavin, M.A. (2005). Omeprazole-induced slowing of gastrointestinal transit in mice can be countered with tegaserod. Eur. J. Pharmacol. 517: 127-131.

Egorin, M.J., Shah, D.D., Christner, S.M., Yerk, M.A., Komazec, K.A., Appleman, L.R., Redner, R.L., Miller, B.M. and Beumer, J.H. (2009). Effect of protonpump inhibitor on the pharmacokinetics imatinib. Br. J. Clin. Pharmacol. 68: 370-374.

Geldof, H., Van der Schee, E.J., Van Blankenstein, M. and Grashuis, J.L. (1986). Electrogastrographic study of gastric myoelectrical activity in patients with unexplained nausea and vomiting. Gut 27: 799808.

Ghoos, Y.F., Maes, B.D., Geypens, B.J., Mys, G., Hiele, M.I., Rutgeerts, P.J. and Vantrappen, G. (1993). 
Measurement of gastric emptying rate of solids by means of a carbon-labeled octanoic acid breath test. Gastroenterology 104: 1640-1647.

Hamilton, J.W., Bellhsene, B.E., Reicherlderfer, M., Webster, J.G. and Bas, P. (1986). Human electrogastrograms. Comparosion of surface and mucosal recordings. Dig. Dis. Sci. 31: 33-39.

Hirako, M., Kamiya, T., Misu, N., Kobayashi, Y., Adachi, H., Shikano, M., Matsuhisa, E. and Kimura, G. (2005). Impaired gastric motility and its relationship to gastrointestinal symptoms in patients with chronic renal failure. J. Gastroenterol. 39: 233-241.

Jebbink, H.J.A., van Berge-Henegouwen, G.P., Bruijs, P.P.M., Akkerman, L.M.A. and Smout, A.J.P.M. (1995). Gastric myoelectrical activity and gastrointestinal motility in patients with functional dyspepsia. Eur. J. Clin. Invest. 25: 429-437.

Koch, K.L., Stern, R.M., Stewart, W.R. and Vasey, M.W. (1989). Gastric emptying and gastric myoelectrical activity in patients with diabetic gastroparesis: Effect of long-term domperidone treatment. Am. J. Gastroenterol. 84: 1069-1075.

Lin, Z., Eaker, E.Y., Sarosiek, I. and McCallum, R.W. (1999). Gastric myoelectrical activity and emptying in patients with functional dyspepsia. Am. J. Gastroenterol. 94: 2384-2389.

Maes, B.D., Ghoos, Y.F., Hiele, M.I. and Rutgeerts, P.J. (1997). Gastric emptying rate of solids in patients with nonulcer dyspepsia. Dig. Dis. Sci. 42: 1158-1162.

Mathur, R., Pimentel, M., Sam, C.L., Chen, J.D.Z., Bonorris, G.G., Barnett, P.S. and Lin, H.C. (2001). Postprandial improvement of gastric dysrhythmias in patients with type II diabetes. Identification of responders and nonresponders. Dig. Dis. Sci. 46: 705-712.

Miyasaka, K., Ohta, M., Kanai, S., Yoshida, Y., Sato, N., Nagata, A., Matsui, T., Noda, T., Jimi, A., Takiguchi, S., Tanaka, Y., Kawanami, T. and Funakoshi, A. (2004). Enhanced gastric emptying of a liquid gastric load in mice lacking cholecystokinin-Breceptor: a study of CCK-A,B, and AB receptor gene knockout mice. J. Gastroenterol. 39: 319-323.

Parkman, H.P., Miller, M.A., Trate, D., Knight, L.C., Urbain, J.L., Maurer, A.H. and Fisher, R.S. (1997). Electrogastrography and gastric emptying scintigraphy are complementary for assessment of dyspepsia. J. Clin. Gastroenterol. 24: 214-219.

Parkman, H.P., Urbain, J.L., Knight, L.C., Brown, K.L., Trate, D.M., Maurer, A.H. and Fisher, R.S. (1998). Effect of gastric acid suppressants on human gastric motility. Gut 42: 243-250.

Perri, F., Clemente, R., Festa, V., Annese, V., Quitadamo, M., Rutgeerts, P. and Andriulli, A. (1998). Patterns of symptoms in functional dyspepsia: role of Helicobacter pylori infection and delayed gastric emptying. Am. J. Gastroenterol. 93: 2082-2088.

Quartero, A.O., de Wit, N.J., Lodder, A.C., Numans, M.E., Smout, A.J. and Hoes, A.W. (1998). Disturbed solid-phase gastric emptying in functional dyspepsia: a meta-analysis. Dig. Dis. Sci. 43: 20282033.

Rasmussen, L., Qvist, N., Oster-Jorgensen, E., Rehfeld, J.F., Hoist, J.J. and Pedersen, S.A. (1997). A double-blind placebo-controlled study on the effects of omeprazole on gut hormone secretion and gastric emptying. Scand. J. Gastroenterol. 32: 900-905.

Sarnelli, G., Caenepeel, H., Geypens, B., Janssens, J. and Tack, J. (2003). Symptoms associated with impaired gastric emptying of solids and liquids in functional dyspepsia. Am. J. Gastroenterol. 98: 783-788.

Smout, A.J.P.M., Schee, E.J.V.D. and Grashuis, J.L. (1980). What is measured in electrogastrography? Dig. Dis. Sci. 25: 179-187.

Stanghellini, V., Tosetti, C., Paternico, A., Barbara, G., Morselli-Labate, A.M., Monetti, N., Marengo, M. and Corinaldesi, R. (1996). Risk indicators of delayed gastric emptying of solids in patients with functional dyspepsia. Gastroenterology 110: 1036-1042.

Stern, R.M., Koch, K.L., Stewart, W.R. and Lindblad, I.M. (1987). Spectral analysis of tachygastria recorded during motion sickness. Gastroenterology 92: 92-97.

Sun, W.M., Smout, A., Malbert, C., Edelbroek, M.A.L., Jones, K., Dent, J. and Horowitz, M. (1995). 
Relationship between surface electrogastrography and antropyloric pressures. Am. J. Physiol. 268: G424-G430.

Tack, J., Talley, N.J., Camilleri, M., Holtmann, G., Hu, P., Malagelada, J.R. and Stanghellini, V. (2006). Functional gastroduodenal disorders. Gastroenterology 130: 1466-1479.

Talley, N.J., Stanghellini, V., Heading, R.C., Koch, K.L., Malagelada, J.R. and Tytgat, G.N.J. (1999). Functional gastroduodenal disorders. Gut 45 (Suppl II): II37-II42.

Tougas, G., Earnest, D.L., Chen, Y., van der Koy, C. and Rojavun, M. (2005). Omeprazole delays gastric emptying in healthy volunteers: an effect prevented by tegaserod. Aliment. Pharmacol. Ther. 22: $59-65$. 